\title{
Comunidades quilombolas e a garantia dos direitos territoriais: as ações da Comissão Pró-Índio de São Paulo
}

A Comissão Pró-Índio de São Paulo (CPISP) é uma organização não-governamental que tem como beneficiários os povos indígenas e as comunidades remanescentes de quilombo do Brasil.

Fundada em 1978 por antropólogos, advogados, professores universitários e médicos, a CPI-SP conta com uma longa história de realizaçóes ${ }^{1}$. Dentre elas, estão as primeiras mobilizações contra a "falsa emancipação dos índios", em 1978; a presença atuante na Constituinte, entre 1986 e 1988; a luta contra os megaprojetos hidrelétricos e a favor dos atingidos pelas barragens, a proposição de alternativas para a política energética no Brasil e a conquista da primeira titulação de terras de quilombos no Brasil, em 1995.

A questão quilombola entrou na pauta dessa organização em 1989, por meio do programa de apoio às populaçóes atingidas por empreendimentos hidrelétricos. Naquele ano, a CPI-SP foi convidada por órgãos da Igreja Católica a auxiliar na organizaçáo das comunidades quilombolas no Vale do Ribeira (SP) e no rio Trombetas (PA), que estavam ameaçadas por projetos de barragens. A partir dessa primeira experiência, a CPI-SP estruturou um programa específico para atuar na defesa dos direitos dessas comunidades e no apoio à sua organização.

Nos 17 anos que se seguiram, observamos que a questão quilombola ganhou maior visibilidade política. Entendemos que esse processo

1. Para saber mais sobre essa história, consulte: www. cpisp.org.br. se deve, em grande medida, à própria organização das comunidades, visando a garantia de um direito assegurado pela Constituiçáo de $1988^{2}$. E esse fenômeno envolve uma série de atores, como movimentos sociais, ONGs, antropólogos e historiadores ligados a universidades e o próprio governo que tem de lidar com uma demanda crescente.

Visando fortalecer esse processo, bem como contribuir com a garantia dos direitos das comunidades quilombolas, a CPI-SP dedica-se a pesquisar e divulgar como os mesmos vêm sendo reconhecidos na legislaçáo, implementados pelo governo e interpretados pelo Poder Judiciário. São três as linhas de pesquisa e monitoramento:

\section{Legislaçáo}

Desde 2002, o sítio eletrônico da CPI-SP apresenta uma relação das disposiçóes legais e regulamentares (federais e estaduais) referentes às comunidades quilombolas que é atualizada semestralmente. $\mathrm{O}$ repertório apresenta também uma seção internacional dedicada à legislação de Colômbia, Equador, Nicarágua e Honduras, assim como aos instrumentos internacionais.

É possível consultar os textos das leis e também os artigos produzidos pela equipe da CPISP no endereço eletrônico:

www.cpisp.org.br/htm/conheca_quilombos.

2. Trata-se do artigo 68 do Ato das Disposiçôes Constitucionais Transitórias. Diz ele: "Aos remanescentes das comunidades dos quilombos que estejam ocupando suas terras, é reconhecida a propriedade definitiva, devendo o Estado emitir-lhes títulos respectivos". 
htm.

\section{Processos de regularizaçáo das terras de quilombo}

Desde 2004, a CPI-SP monitora os processos de regularização de terras de quilombo em curso nas diversas Superintendências Regionais do Instituto Nacional de Colonização e Reforma Agrária (INCRA). Atualmente, são monitorados 327 processos que tramitam em 21 estados $^{3}$.

A principal fonte de informação é o próprio INCRA. Os dados são obtidos junto à equipe de procuradores, engenheiros agrônomos e assessores técnicos daquele órgão. A coleta de informaçóes envolve também visitas às superintendências, acompanhadas de uma pesquisa periódica ao Diário Oficial da Uniáo e em sítios eletrônicos que divulgam a questão quilombola.

As informações obtidas são continuamente cadastradas em um banco de dados e se encontram acessíveis ao público para consulta por meio de diversas formas de busca no sítio-eletrônico: www.cpisp.org.br/terras.

\section{Açóes judiciais}

Em 2005, a CPI-SP iniciou o levantamento das diversas ações judiciais envolvendo terras de quilombo. Até outubro de 2006, havia sido levantadas e sistematizadas informaçóes sobre 93 açóes envolvendo 28 territórios em 12 estados, sendo que, desse total, 56 ainda estão em curso.

O monitoramento inclui ainda a análise das diversas peças dos processos e o acompanhamento de seu andamento pelos sítios eletrônicos da Justiça Federal e Estadual. As informações são obtidas junto a órgãos governamentais (federais e estaduais), ao Ministério

3. Os números aqui mencionados datam de outubro de 2006.
Público Federal e a organizaçóes não-governamentais.

Os primeiros resultados da referida pesquisa, bem como uma coletânea das mais significativas sentenças de forma a construir um repertório de jurisprudência que possa servir de instrumento aos quilombolas podem ser acessadas em: www.cpisp.org.br/acoes

\section{Breve panorama da situaçáo atual}

De acordo com os dados levantados pela CPI-SP, até outubro de 2006, 59 terras de quilombo encontravam-se tituladas. Esse conjunto de titulaçóes envolve 116 comunidades, uma população de 7.195 famílias e uma área de $907.488,4790$ hectares.

A maior parte desses títulos (25) foi outorgada pelo Governo do Pará. O Pará é o estado com maior número de terras tituladas (31 terras) e também com a maior dimensão. Os 533.196 hectares de terras quilombolas tituladas naquele estado representam $59 \%$ da dimensão total titulada no Brasil.

O levantamento da CPI-SP indicava também a existência de 327 processos de regularização de terras de quilombo em curso no INCRA. Verifica-se uma ampla distribuição dos processos entre os estados. Das 23 unidades da federação em que se conhece a existência de comunidades quilombolas, 21 têm processos abertos pelo INCRA. Ou seja, em quase todos os estados com presença de quilombolas há processos em andamento. Já se superou, portanto, aquela etapa inicial em que a açáo do INCRA estava concentrada no estado do Pará. Lembramos que entre 1995 e 1998, o governo federal apenas titulou terras quilombolas localizadas nesse estado.

Avaliamos que tal fato deve-se, em grande medida, à maior organização dos movimentos quilombolas, representados pelas associaçóes comunitárias e organizaçóes estaduais e nacionais. 
Anteriormente, a mobilizaçáo dos quilombolas estava restrita a poucos estados: Maranhão, Pará, Pernambuco, São Paulo e Bahia. Hoje, a questão está em pauta em todo o Brasil.

Entendemos que há uma relação dinâmica entre a atuação política dos quilombolas e as açóes governamentais. Nesse sentido, o fato de o movimento quilombola estar cada vez mais organizado explica a ampla distribuição dos processos pelas regionais do INCRA. Um bom exemplo é o caso de Minas Gerais. Em junho de 2005, existiam cerca de 20 processos abertos pela Superintendência do INCRA em Minas Gerais. Em outubro de 2006, esse número triplicou, somando 62 processos no total. Esse rápido aumento de processos naquele estado coincide com a crescente organização dos quilombolas mineiros que teve como marco a fundação da Federação Estadual das Comunidades Quilombolas de Minas Gerais (N'golo) em junho de 2005.

É difícil estimar qual a população e a extensão de terras envolvidas nos processos em andamento, já que muitos ainda não apresentam essa informação. Apenas 194 processos contam com uma estimativa de população que soma 18.799 famílias. Número ainda menor de processos (143) contém uma estimativa de extensão de terras a serem tituladas que totaliza 1.114.765 hectares.

A comparação entre o número de processos atualmente em curso no INCRA (327 processos) e o total de títulos emitidos ao longo de 11 anos (59 títulos) revela um incremento considerável nas iniciativas governamentais relativas a essa categoria de terras. No entanto, não há muito que comemorar, já que essas iniciativas geraram, até o momento, poucos resultados efetivos, ou seja, terras tituladas e livre de invasores. O Governo Lula, até outubro de 2006, havia titulado apenas quatro terras quilombolas.

Embora o número de processos abertos seja bastante impressionante, o que se observava é que 61\% (199 processos) apenas receberam um número de protocolo, ou seja, não foram alvo de qualquer medida. Em suma, o INCRA ainda não tem sido capaz de atender a demanda com eficiência.

Do conjunto de 327 processos, apenas 41 tinham concluído a etapa de produção do relatório técnico de identificação (13\% dos processos), ou seja, tinham os limites do território identificados e a situação fundiária levantada.

Vale destacar, porém, alguns recentes avanços oficializados pouco antes das eleiçóes presidenciais. Em outubro de 2006, a Secretaria de Patrimônio da União (SPU) outorgou um título a parte do território da comunidade de Parateca e Pau D’Arco, na Bahia. É a primeira vez, na história dessa instituição, que um título definitivo é expedido. Até então, a SPU outorgara apenas concessóes de uso do território ${ }^{4}$.

Outro precedente importante foi a assinatura dos decretos de desapropriação por interesse social de propriedades incidentes nos territórios de Caçandoca (em São Paulo) e Família Silva (no Rio Grande do Sul). Até essa data, existiam apenas dois casos de desapropriação de terras de quilombo, ambas iniciativas do Governo do Pará datadas de 2002.

A desapropriação atende a uma antiga reivindicação dos quilombolas, que consideram esta a forma de agilizar a titulação e garantir o pleno acesso aos seus territórios. E, tanto Caçandoca quanto Família Silva, possuem uma longa história de conflitos com particulares.

Esperamos que os casos aqui mencionados abram precedentes para novas açóes nesse sentido e que, nessa nova gestão que se inicia em 2007, o governo federal atenda de fato a essa crescente demanda das mais de mil comunidades quilombolas existentes em todo o Brasil.

4. A Secretaria de Patrimônio da União é um órgão do Ministério do Planejamento responsável pelos terrenos de marinha do país, ou seja, ilhas, praias e várzeas. Todos os terrenos de marinha pertencem, a princípio, à União. 
276 | As açốes da Comissão Pró-Índio de São Paulo

SÍTIO ELETRÔNICO

www.cpisp.org.br

CONTATOS

cpi@cpisp.org.br [institucional]

terra-quilombo@cpisp.org.br [para o monitoramento de processos administrativos e judiciais em terras quilombolas]

EQUIPE

Coordenadora Executiva: Lúcia M.M. de Andrade

Coordenadora do Programa Povos Indigenas: Selma Aparecida Gomes

Coordenadora do Programa Comunidades Quilombolas: Lúcia M.M. de Andrade

Gerente Administrativa: Claudia Regina Ferreira de Sousa

Auxiliar de contabilidade: Lourival dos Santos Souza

Auxiliar de secretaria: Luciano Evangelista Filho

Consultoria para o monitoramento de processos administrativos e judiciais em terras quilombolas: Ana Carolina da Matta Chasin e Daniela Perutti 